\title{
Teachers' emotional responses to new pedagogical tools in high challenge settings: illustrations from the Northern Territory
}

\author{
Helen Harper
}

Published online: 26 September 2012

(C) The Author(s) 2012. This article is published with open access at Springerlink.com

\begin{abstract}
This paper explores the role of teachers' emotions in adopting new pedagogical tools in urban and remote schools in the Northern Territory. The discussion is illustrated through case study material of Northern Territory teachers who had taken up using a web-based early childhood literacy resource called ABRACADABRA. A sociocultural perspective is used to examine the relationships among the teachers, the new resource, and teachers' emotional responses to using the resource. The ABRACADABRA case study material suggests that the teachers did not embrace using the new tool purely on the basis of their ability and willingness to use it. Rather, the whole school context played an important role in both technical and emotional support for teachers. Teachers' negative feelings of frustration and reluctance to use the new tool, as well as their positive feelings of confidence and fun, were triggered in part by their own interaction with the tool, but also by other factors within the school environment, such as collegial support. Hence, the emotional filters through which teachers thought about ABRACADABRA themselves became a mediating factor in their use of the tool. This study has implications for how we conceptualise teachers' adoption of new resources in challenging settings such as Indigenous education, and highlights the relationship between teacher effectiveness and their feelings about their work.
\end{abstract}

Keywords Computer technology adoption - Teacher emotions · Indigenous education $\cdot$ Literacy $\cdot$ Mediated action

H. Harper $(\square)$

Menzies School of Health Research, Darwin, NT, Australia

e-mail: helen.harper@menzies.edu.au 


\section{Introduction: the discourse of teachers and tools in the Northern Territory}

As a discursive terrain, the question of how teachers adapt to the continually challenging context of remote and Indigenous education in the Northern Territory (NT) of Australia is highly emotionally charged. A significant part of this is arguably the anxiety that arises from the grindingly regular reiteration of dismal statistics relating Indigenous children's performance in schooling. ${ }^{1}$ There is no shortage of explanations for why education in the north does not appear to be working for the most disadvantaged children: the list of contributing factors often cited includes economic disadvantage, poor attendance rates, and the remoteness of many Indigenous communities, along with the non-English speaking background of the children, the prevalence of otitis media and related hearing loss, high rates of teacher turnover, and a shortage of teachers trained specifically to teach Indigenous students (Aithal et al. 2008; Beresford and Gray 2006; Bourke et al. 2000; Collins and Lea 1999).

Increasingly in public debate, however, it is teachers who are positioned as "the problem", and subsequently repositioned as the solution (Luke et al. 2010, p. 13) often through talk about notions such as "academic preparedness, workforce diversity, and capacity to engage with cultural diversity" (Warren Little and Bartlett 2010). Hence, the question of the "best way to teach" is always at the surface of the public consciousness, with the discourses of "improved performance" and "accountability" pursuing teachers throughout their everyday practice. Commentary from the sidelines constructing the situation as a crisis and a failure of teacher know-how (e.g., Hughes and Hughes 2010; Pearson 2009, 2010) adds to the pressure on teachers to do more, to do better, and to take on new ways of doing things.

At the same time, teachers are also faced with conflicting messages about how to teach. Official rhetoric about how to address poor educational outcomes in the Northern Territory is somewhat ambivalent about the programs and pedagogical tools teachers should use. There is justifiable wariness of simply picking up any ready-made resource. A recent structural review of the NT Department of Education and Training (Ladwig and Sarra 2009) found a "preponderance of unrelated initiatives based on the search for the 'silver bullet'-reflecting a lack of systemic coherence". ${ }^{2}$ They also observed that "while any one innovative program may be well defended as having potentially beneficial educational effects, without coordinated and sustained implementation, there is little reason to believe any one program on its own will have enduring effects" (p. 22). Still, with the onus on schools or even individual teachers to be innovative in their teaching to suit their own contexts, it seems that teachers are asked to be receptive to new tools, while

\footnotetext{
1 A striking visual image of comparative Australian educational outcomes is the "tail" representing NT Indigenous students on annual graphs of National Assessment Program in Literacy and Numeracy (NAPLAN) reports. For example, in 2011, while $93.8 \%$ of Year 3 students across Australia achieved at or above the national minimum standard in reading, the percentage for Year 3 NT Indigenous studentswho make up nearly half of the student population in the NT-was only $39.9 \%$ (Australian Curriculum Assessment and Reporting Authority 2011, p. 4).

${ }^{2}$ For an account of the large number of such initiatives that have been proposed to help tackle Indigenous education, see Ramsey et al. (2009).
} 
being wary of them at the same time, particularly if they do not come packaged with strong approval from the system. Potentially, this represents a stressful conundrum for teachers.

This paper explores teachers' emotional responses to adopting a new pedagogical tool in urban and remote schools in the NT. My aim is to raise the question of how we conceptualise new tools or programs in high-challenge settings such as the Northern Territory, and to posit the role of teachers' feelings as essential to how they adopt new ways of working. I suggest that we tend primarily to look to the rational relationships between teachers and their approaches to teaching, but less frequently consider, in the discourse of educational reform at least, how teachers actually feel about their teaching work, and the extent to which this has a bearing on their effectiveness as teachers. The purpose of this paper is to take some preliminary steps to examine the emotional landscape of Indigenous and North Australian education, and to explore how we might begin to see teachers' emotions both as an integral part of their cognition and as part of what mediates their decisions about how they teach.

To illustrate my discussion, I draw on material from case studies in four Northern Territory schools in which teachers were asked to trial the use of a pedagogical tool: a free web-based early literacy resource, ABRACADABRA (ABRA). The aim here is neither to promote nor critique ABRA as a solution, or even as a pedagogical resource, but rather to examine the complex demands of adopting new pedagogical practices and to explore the relationships between teachers and the tools they use to help them teach. ABRA is an example of one such tool, and, as such, allows us to examine the scenario of its uptake from the perspective of teachers' emotions.

\section{A sociocultural perspective}

A sociocultural perspective is useful for considering the teacher-tool relationship as it requires that we take into account the larger context of teachers' professional and affective activity, incorporating such elements as the whole school environment, teaching goals, and system support for teachers. This perspective draws from the work of Vygotsky (1986), who critiqued the traditional psychological separation of studies of intellect and affect, arguing that this made "the thought process appear as an autonomous flow of 'thoughts thinking themselves', segregated from the fullness of life, from the personal needs and interests, the inclinations and impulses, of the thinker" (p. 10). Vygotsky suggested that emotions are instead fundamental to such functions as motivation, planning, and action. As noted by Smagorinsky and Daigle (2012), a major implication of Vygotsky's thinking is that "people frame and interpret their experiences through both emotional and cognitive means working in tandem" (p. 295). Additionally, Smagorinsky and Daigle have suggested that people make sense of the events in which they are involved by constructing positive or negative meta-experiences or "experiences of their experiences", thus interpreting experience through emotions serving as "mediational tools" (p. 295).

The notion of mediational tool, essential in Vygotsky's thinking, has been further developed by Wertsch (1998), for whom a pedagogical tool can be seen as an 
organisational means-material or symbolic - through which a teacher constructs pedagogical activity. Wertsch emphasised the need to view the relationship between "agent" (in this case the teacher) and "tool" (in this case a resource such as ABRA) as a whole unit. In Wertsch's (1998) words, "any attempt to reduce the account of mediated action to one or the other of these elements runs the risk of destroying the phenomenon under observation" (p. 25). It follows that there is limited value in examining the tool or the teachers as independent entities and attributing pedagogical success or failure to one or the other. Rather, taking account of what Wertsch (p. 25) refers to as the "irreducible tension" between agents and their tools leads us to focus both on how the teacher works with the tool and on teachers' responses to what the tool allows them to do.

\section{Teaching as emotional work}

A growing body of research (e.g., Hargreaves 1998, 2001; Kelchtermans 2005; Little 1996; Nias 1996; O'Connor 2008; Sutton and Wheatley 2003; Zembylas 2002) argues that teaching cannot be reduced to technical competence or state standards, but rather involves significant emotional understanding and labor. Indeed, Hargreaves (2001) suggests that "teaching and learning are irretrievably emotional in nature" (p. 1056). The emotions that teachers experience are both positive and negative: teachers need to feel positive emotions such as enjoyment, excitement, and enthusiasm to do an effective job (Hargreaves 1998, p. 838), but they also frequently experience negative feelings such as frustration, disappointment, guilt, anger, sadness, embarrassment, anxiety, and feelings of powerlessness (Little 1996; Zembylas 2002). There are many emotional tensions in teaching. Nias (1993), for example, has documented the feelings of grief or loss that primary school teachers experience when an imposed curriculum prevents them from pursuing the educational purposes they believe to be most important. Further, as Hargreaves (1998, p. 839) has commented, emotional misunderstanding is a chronic feature of many schools and classrooms. This happens not so much because teachers do not care about their work, but because many of the structures of schooling (timetables, preoccupation with content and standards) may leave teachers little time or space for successful emotional understanding of students. Following Hargreaves, O'Connor (2008) also argues that although caring is one of the predominant and visible emotions that teachers demonstrate in their work, it is generally ignored and marginalised in the politics of educational reform and administration, leaving some teachers feeling that you can "care too much" (p. 121).

Emotions affect teachers' actions: they shape cognition, and may potentially influence attention, memory, and problem-solving (Sutton and Wheatley 2003, p. 336). For example, negative emotions intrude on consciousness, potentially distracting teachers and diverting attention from instructional goals. Further, research suggests that emotional stimuli are often remembered better than unemotional stimuli. Emotions can also affect the level of challenge in goals that teachers choose, so feeling positive may lead teachers to set more challenging learning goals for students, and to conceive more ambitious goals for their own teaching. 
Hargreaves (1998) argued that emotions need to be studied within the process of educational change, as opposed to treating educational change as simply a rational process that pursues rational ends. In this context, emotions can be viewed as more than just part of teachers' individual reality; they are also part of the social, political, and cultural contexts of the work teachers do (Zembylas 2002). Hence, in keeping with a sociocultural perspective, emotions can be understood as both a biological and a social construction, mediated by social structures, cultural tools, and identity (Lasky 2005).

\section{Indigenous education and teachers' emotions}

Despite the sizable literature on emotions in teachers' work, there is little that addresses the emotions of teachers in remote and Indigenous contexts. ${ }^{3}$ Nonetheless, the remote Indigenous context offers some specific emotional challenges for teachers. As Hargreaves (1998, pp. 839-840) has noted, when teachers come from different ethnocultural or social backgrounds from their students, there is greater potential for misunderstandings that can seriously interfere with teachers' ability to help students learn. In remote communities, teachers might find it difficult to engage parents for various reasons, including not speaking the same language, parents feeling uncomfortable in the physical space of the school, tensions with high student absenteeism, and a general lack of school-community engagement. In a system where student failure is presented as endemic, both publicly and within the teaching system, we can predict that teachers are likely to feel some limits to their own effectiveness, and that they might encounter some feelings of helplessness, guilt, or sadness.

Teachers are also likely to experience vulnerability (Kelchtermans 2005, p. 997) if, as is often the case, many of their working conditions appear out of their control. For example, housing in remote schools is frequently inadequate, teachers are likely to lack familiarity with their students' culture and language, and they have almost no control over student attendance and the high levels of turnover of their colleagues (see, for example, Lea et al. 2011). On the other hand, there is a dearth of research relating to positive emotions that teachers may feel working in crosscultural contexts. These conceivably might derive from feeling successful in their work, or enthusiasm for travelling to new places and creating new friendships, or learning to live in a new culture.

\section{Background to the ABRACADABRA study}

To illustrate the concepts above, I now turn to ABRA, and its use in the setting of NT schools. As noted above, ABRA is a free web-based teaching resource for early literacy instruction. It was developed in 2002 by a team of literacy and classroom technology experts at Concordia University, Canada. ABRA's creators were informed by recommendations from the United States National Reading Panel

\footnotetext{
3 See, however, Sharplin (2002); Yarrow et al. (1999) who, respectively, deal with pre-service teachers' expectations of rural and remote teaching, and more general issues relating to teaching in remote contexts.
} 
(National Institute of Child Health and Human Development 2000), with the aim of improving the literacy of students aged four to eight at risk of school failure (Hipps et al. 2005). Subsequent experimental and quasi-experimental studies have shown ABRA to be a highly effective resource for teaching early literacy (Comaskey et al. 2009).

ABRA comprises 32 instructional activities embedded in 17 stories. The interface is game-like, with quirky, edgy characters designed to "hook" children in. Activities are organised into the foundations of literacy acquisition (alphabetics, fluency, comprehension, and writing), so teachers can guide students from basic skills to complex tasks. Teachers can use ABRA for whole class instruction (e.g, via interactive whiteboard), or for students working at computers individually or in pairs. ABRA is not intended as a whole literacy program, but relies on teachers to choose the skills that students need most practice, for integration into their broader literacy work.

ABRA was first trialled in the NT in 2008, and over the following 3 years researchers ${ }^{4}$ from Charles Darwin University worked with teachers who agreed to use ABRA in a rigorous manner to evaluate its effectiveness in schools. Studies established ABRA's effectiveness in urban and remote primary schools with a mix of Indigenous and non-Indigenous students under quasi-experimental and experimental conditions (Wolgemuth et al. 2011). ${ }^{5}$

\section{The ABRACADABRA case studies}

The 3 year ABRA studies offered a high level of support to teachers, and researchers frequently visited schools to observe classes and offer advice and assistance to the teachers. That ABRA was used effectively under these controlled study conditions, however, is not of itself an indication of how well teachers could use it with much lower levels of support, as is typical for other literacy programs in the NT. To understand how the tool would be used in more "naturalistic" conditions, I was part of a team who carried out case studies in four schools (two urban and two remote) in 2010, where teachers trialled the integration of ABRA into their literacy instruction with only minimal training and support.

All case study schools serviced populations with high proportions of low income, welfare dependent families. The two urban schools (in Darwin and Palmerston) were

\footnotetext{
4 The 3 year trial involved a partnership between the Centre for the Study of Learning and Performance, the Menzies School of Health Research and Charles Darwin University, and was funded by the Telstra Foundation, the Fred Hollows Foundation, Colliers, the Australian Institute for Aboriginal and Torres Strait Islander Studies and the Australian Research Council [LP0990171].

5 It is beyond the scope of this paper to offer a detailed analysis of the appropriateness of ABRA to the NT context. The initiators of the NT ABRA study argued that as a set of computer-based activities, ABRA gives early childhood teachers a practical and economical means for organising their teaching of basic literacy skills (Harper et al. 2012). Although not specifically created for Indigenous contexts, ABRA had nonetheless been designed to be used by English language learners (many from French-speaking or immigrant backgrounds) in English-medium schools in Montreal. ABRA was thus potentially suitable for the multilingual context of Northern Territory, where children's home languages often include traditional Aboriginal languages, Kriol, Aboriginal English, and immigrant languages.
} 
highly multicultural, and one had a significant cohort of children from a nearby Aboriginal enclave as well as from a neighbouring RAAF base; both highly transient populations. The other was located in a low socio-economic area with a high immigrant and Indigenous population. The third case study school was located in the small town of Katherine, $3 \mathrm{~h}$ drive from Darwin. The majority of these students were Indigenous, with many from nearby welfare housing or town camps. ${ }^{6}$ The final school, also with mostly Indigenous students, was located in a small town south-west of Katherine. In these last two schools, students' home languages mostly ranged from varieties of Aboriginal English (phonologically and grammatically similar to standard English) to varieties of Kriol that are quite distinct from standard English (Harris 2007). Some students also spoke one or more traditional Aboriginal languages.

Hence, a large number of children in the four schools was Indigenous and many were learning English as an additional language, which was also the language of instruction in each setting. All schools had relatively high rates of student mobility, particularly amongst Indigenous students whose families may move relatively frequently between towns and remote communities, or other centres where they have family ties (Taylor and Dunn 2010). Additionally, all schools experienced high rates of teacher turnover.

To participate in the research, early childhood teachers were given a day's training in using ABRA. They also received a support visit from a researcher, who offered feedback on the structure or content of the ABRA lessons, and advice on any technological problems. At the end of one semester, pairs of researchers visited the schools once more to observe the teachers in class and interview teachers, support staff, school leaders and some students. For lesson observations we used a semi-structured observation record that had been developed as a program fidelity measure for ABRA (Wolgemuth et al. 2011) and also took open-ended field notes about the lessons, the classrooms and the school environment. Along with some short interviews with students, we carried out 11 semi-structured interviews with school staff of about an hour each, six of which were with the classroom teachers. The interviews were transcribed in full, and then, together with our field notes, were coded into emergent themes with the help of NVivo qualitative data analysis software.

The ABRA case study findings have been described in detail elsewhere (Harper et al. 2012). In brief, however, without the level of support provided to the experimental trial schools, the implementation of ABRA in the case study schools was inconsistent and largely ineffective. It seems important to reiterate that this was in contrast to how teachers in the controlled studies had used ABRA; that is, ABRA could be well implemented in the NT, under the right conditions.

It was clear that most of the teachers we observed were still in the process of learning how to work with ABRA. In cases where teachers were able successfully to incorporate ABRA into their literacy instruction, the relationship between teachers

\footnotetext{
6 Town camps are quasi-permanent Indigenous settlements usually located on town peripheries. Despite proximity to service centres, they typically have poor infrastructure and high rates of social disadvantage.
} 
and ABRA could be analysed in relation to their existing levels of technological skill and their ability to conceptualise their literacy program more broadly. Teachers' underpinning skills came to the fore in interviews, when a number of teachers stated they did not believe their training had adequately prepared them to teach children to read.

There is clearly a lesson here about the levels of support necessary for pedagogical innovations in high challenge contexts. However, a further lesson is potentially to be found in probing the relationships amongst teachers, the new resource, and the teachers' motivations for learning to use it. To explore these relationships, I revisited the case study observations and interviews to find evidence of how the teachers felt about using ABRA and the triggers for those emotions. ${ }^{7}$ In keeping with the sociocultural approach, I looked for evidence of how the whole school environment impacted on the teachers, including, for example, how schools were organised, the teachers' relationships with colleagues, how the children were organised into classes, and how the use of ABRA interacted with other pedagogical practices.

The following section presents some of the ways in which, on revisiting the data, I found four of the teachers-Jess, Lucy, Nina, and Justine (pseudonyms) framed their thinking about ABRA within a larger discourse about their feelings for their work. These teachers were notable because they presented themselves to the researchers as having made some genuine effort to incorporate the tool into their practice and of having giving it their "best shot". At issue here is not whether they were effective, but what feelings ABRA triggered for them when they were using it.

To examine emotions using this data presents a number of limitations. Clearly, I could not "know" in any objective sense what teachers felt. My commentary is therefore drawn from my necessarily subjective interpretations of what was observed in the classes, and what teachers said in interviews. Further, in examining teachers' words, I could not rely on them to talk about their feelings "honestly", on the assumption they might have felt it unacceptable to criticise their colleagues to outsiders. At the same time, I also found emotions were often manifest in the way teachers talked, such as the intensity of their speech (Roth 2007). On the whole, however, the data are necessarily sketchy and subjective. The commentaries that follow are not intended as in-depth analyses of teachers' emotions. Rather, they are intended to encapsulate the "feel" and emotional energy of teachers' work in an illustrative and exploratory fashion, and to highlight the points made earlier about how emotions impact and mediate teachers' practice.

\footnotetext{
7 Some researchers (e.g., Holodynski 2009) differentiate carefully between "emotion" and "feeling" in order to describe emotional development and the complex interaction between emotions and social interactions. For the purposes of the current discussion a strict distinction is not so important: the term "feelings" is used to refer to the sensations that are triggered by the teachers' perceptions of the situations in which they used ABRA, as well as to their ways in which their emotions are experienced and made conscious.
} 


\section{Teachers' responses to ABRA}

Frustrations of the tool and the whole school setting

Jess's classroom was meticulously arranged and decorated: the walls neatly adorned with words, sounds, and letters for children at different reading levels. From the tidiness of her room, Jess appeared to like things well organised, and was perhaps not comfortable with leaving things to chance. We watched her smoothly manage a highly diverse group of Transition/Year 1 children into reading groups without major incident. She projected a confident teaching identity firmly grounded in her classroom skills. In her view, anyone peddling "methods" or "innovations" would need to court her with an exceptional presentation, and anything too prescriptive would be a "turnoff." She would not tolerate half-baked ideas about teaching, and was direct and unapologetic when she told us: "I don't want to hear any rubbish, give it to me straight."

Jess echoed the sentiments of most of our case study teachers in commenting on all the ways that using ABRA could go wrong. She explained how "really, really frustrating" it could be when technology failed, and when she found herself managing groups of children who "aren't going to do what's needed and it's all behaviour management, or it's all frustration because they're not actually playing the games and practicing the skills." Jess was cognizant, too, of the need to be attentive to younger children: "that can be really frustrating [...] because kids don't always say anything right away [when they get stuck with the computer] because they are still very young."

For Jess, ABRA's most obvious affordance as a mediational means - its engaging computer interface - was perhaps also its most serious constraint, with the technology itself engendering constant major and minor frustrations for teachers. Technological problems observed throughout our school visits-games freezing mid-lesson, no sound for the interactive whiteboard or computers-were minor in isolation, but together with the myriad other disruptions that schools face daily had the potential to seriously impede effective practice, adding to the teacher's stress. Moreover, lessons marred by internet connection failures were more likely to stick in a teacher's memory than "emotionally neutral" lessons where everything went smoothy.

For Jess, such irritations spread beyond her use of ABRA to the school environment as a whole, where she felt unsupported and unrecognized by her teaching colleagues. She expressed some cynicism about the rhetoric of shared planning within the school ("I don't really know how other people run it at this school"), and yearned for a more collaborative approach to planning and teaching: "I've always found it frustrating up here that schools I've been in in the Territory, people don't plan together". For Jess, ABRA could not alleviate the frustration she felt with the school beyond her classroom, and her feelings about the tool needed to be seen within this larger context.

\section{Growing confidence in isolation}

Lucy differed from the other case study teachers in that she had been using ABRA throughout the 3-year NT study, and benefited from an established relationship with the research team. She was easily the most confident user of ABRA that we 
observed and interviewed, and offered astute comments on the importance of learning to use a new resource and her growing feelings of confidence with it over time. Nonetheless, in her 4th year of teaching at the time of the study, she still felt herself to be a neophyte teacher, and her conversations were peppered with hesitations and self-interrogations about her classroom effectiveness, suggesting some residual insecurity about herself as a teacher.

Lucy made it clear she had experienced a high degree of self-doubt when learning how to use ABRA. In Lucy's teacher-world of "too many things to fit into the day," learning to use ABRA had in itself been stressful, because of the time taken to familiarize herself with the activities and skills, and because she wanted to integrate it into her broader literacy program. Moreover, a high level of teacher turnover meant Lucy had found herself the only teacher in the school with consistent experience in using ABRA. Despite colleagues all speaking very highly of Lucy's skills as teacher, it was clear that being appreciated by her colleagues did not automatically translate into an internal feeling of confidence. Rather, what Lucy seemed to experience was the isolation characteristic of being a pioneer, and while she had shown herself to be resilient, it had often been uncomfortable.

\section{Dialogue to build confidence}

Nina also demonstrated a high degree of confidence and skill in using ABRA. In contrast to Lucy, who had learned to work with ABRA without the benefit of much collegial company, Nina's sense of confidence came from opportunities to work collaboratively with her colleague, Frances. Nina told us that she had initially felt reluctant to use ABRA.

It was one thing for Nina that Frances had previously used ABRA and was comfortable using it. However, most importantly, Nina was willing to try ABRA because she felt Frances shared her situation and understood the context within which they were both working. Nina's reconstructed conversations with Frances illustrated the confidence they had shared, and how her own response to ABRA was shaped by the responses of another. She told us:

For me it was just that Frances had given it a go. Without Frances doing it I probably wouldn't have been too keen. When I first looked at it on the internet I went, "Oh, my God, how am I going to tell my kids how to get around that," and so I went to Frances and she goes, "Oh, no, no, no, ... I thought exactly the same thing but then after a while they just know what is in all of the different areas," and I went, "Oh, okay."

Nina also characterized seeking advice from Frances:

"How about this?" Or for my programming, "This is what I've done for my programming, does that sound right?"

"Yeah, that's fine, that's exactly how I'm doing it."

"Okay no worries."

This was more than a statement from Nina about how Frances had helped her: through playing out the dialogue and reproducing her colleague's reassuring words, Nina reconstructed for us the support that she had felt. 


\section{So emotional}

Justine's class was one of the more chaotic classes that we visited. Her students, in staff room conversations, and with some input from a visiting school psychologist, had all been labeled "problematic" at some level. Within the group were poor attenders and children who, for all manner of reasons (hearing difficulties and other health problems, attention deficit, cultural and linguistic difference, lack of school readiness, and unspecified learning difficulties) were perceived to have trouble learning. We learned that Justine had been assigned this class largely because of her simultaneous traits of physical energy and calm demeanour. Justine's ability to mix tolerance with discipline allowed her to survive the generally unpredictable school day. In the hectic environment of her class, with the need to respond constantly to the hyperactivity of many of the children, the stress she felt manifested in self-talk which she shared cheerfully with us: "brace yourself" (fortifying) and "just breathe" (calming).

Justine's general feeling of high energy was offset by her feeling that the school environment was not supporting her well. Like Jess, she craved a more collaborative environment. She told us emphatically, "I'd love to work in a team", her voice lingering on the word "love."

Justine was still relatively new both to early childhood teaching and to using the ABRA resource, and this manifested in a very fragmented lesson structure in which children flitted between activities on the computers, mostly without engaging in the content. Nonetheless, she was enthusiastic about ABRA and intended to continue to use it. She identified her enthusiasm as being underpinned firstly by the sentiment that ABRA was "kind" to the children, and secondly, by her own experience with the ABRA researcher who had trained her, whom she had found inspirational: "I could imagine her in the class just being great. I could see that she was a kind person. And I thought 'I want to be like you'".

With its cheery interface and funny, quirky characters, ABRA was something she was prepared to persevere with. It was clear from watching Justine's class, and from talking with her subsequently, that whatever tools she used, her fundamental motivation in working with the children was to make sure she engaged with them at a personal level, and they had fun: "I think it's the-what's the word? So emotional. Like it's really ... a bit more caring than just ramming things down their throats."

\section{New tools and teachers' emotions in context}

The teachers in the ABRA case studies were well aware that a given pedagogical tool will not just "work", and were generally cynical that any new resource could truly address their challenges in teaching. They expressed this in their overall wariness towards new approaches, and the almost clichéd sentiment that, as Lucy pondered, "just another thing that comes in and then it's gone again." Although Lucy thought ABRA was useful and liked using it, she wondered whether for many teachers it would seem like "just another thing to be good at."

However, the picture of how teachers take new tools on board is more complex than this picture of "same-old" might suggest. The illustrative sketches of Jess, 
Lucy, Nina, and Justine suggest that teachers do not embrace using a new tool only on the basis of their ability and willingness to use it. Rather, the whole school context plays an important role in both technical and emotional support for teachers. A new tool, particularly a technologically-based one, can cause teachers to be fearful of lessons going wrong in unpredictable ways, which in turn is likely to trigger degrees of frustration and reluctance to use the tool in case it lets them down. And if the school environment also lets teachers down - through lack of collegial support, for example-the frustration and reluctance can become further filtered through a sense of isolation, as teachers in this study reported. Teachers without Lucy's level of resilience may well end up overwhelmed by the challenges of working without support or dialogue, and cease to put the effort into working with a new tool. On the other hand, from a positive example such as Nina's, socially constructing emotions through supportive dialogue can assuage doubts and reassure. Hence, the emotional filters through which teachers think about a tool become themselves a mediating factor in their use of the tool. In Nina's case, for example, her dialogue with Frances remained a part of the way she thought about preparing her ABRA lessons. Moreover, as Roth (2007) has argued, we can expect that through positive emotional responses teachers find the possibility of genuine transformation of practice. This may explain Lucy's resilience and persistence with ABRA, despite her frustrations and self-doubts.

And this is perhaps an explanation for what kept Justine using ABRA. We might say Justine had not yet established her skill in integrating using ABRA into a coherent literacy program, and she had not had the advantage of much collegial support in her school. She was undergoing significant stress in her daily teaching. But notably, Justine did not mention frustration with ABRA or reluctance to use it when she spoke with us. What she emphasised was her affective response to ABRA in the training she had done and in the fun of the games themselves. We could hypothesise that the quest for fun and for good affective relationships with her students offset more negative feelings and allowed her to continue.

The discussion here has been very much exploratory. There are many further questions to examine. This paper has not dealt with broader "emotional geographies of teaching" (Hargreaves 2001): it does not address how teachers relate to children or the emotions of the cross-cultural context, for example.

As a preliminary foray into the question of how teachers in the Northern Territory feel about adopting new tools, this paper nonetheless leads to some interesting directions for further research. We should, following the questions foreshadowed by Sutton and Wheatley (2003, pp. 344-345), for example, seek to better understand why teachers take on some innovations, but resist others. It would also be useful to know whether teachers who feel positively about a new tool are more ambitious in their teaching goals, and the learning goals they set for their students.

Despite educators' wariness of the idea of "silver bullets", the search for "the best ways to teach" is likely to continue to dominate the public debate about remote and Indigenous education. In view of this, it will be beneficial to develop a more sophisticated understanding of how teachers feel when they are asked to adopt new pedagogical tools. Rather than being dismissed out of hand as "yet another thing", new pedagogical tools - along with the frustrations and levels of discomfort that 
they may bring-need to be understood as functions of the whole school context. Dismissing silver bullets has an inherent rhetorical appeal, but then what? Acknowledging the emotions inherent in taking on new tools - and the mediational power of those emotions-will allow us to better understand the process of implementing interventions in schools, and to build a more realistic picture of the teacher-tool relationship.

Acknowledgments I am indebted to the teachers who generously shared their work with me and my colleagues in the course of the fieldwork that informed this study. The ABRA case studies were the work of a team, and I acknowledge and thank Susan Emmett, Kalotina Halkitis, Janet Helmer, Tess Lea, and Jennifer Wolgemuth for their collegiality throughout this project.

Open Access This article is distributed under the terms of the Creative Commons Attribution License which permits any use, distribution, and reproduction in any medium, provided the original author(s) and the source are credited.

\section{References}

Aithal, S., Yonovitz, A., \& Aithal, V. (2008). Perceptual consequences of conductive hearing loss: Speech perception in Indigenous students learning English as a "school" language. Australian and New Zealand Journal of Audiology, 30(1), 1-18.

Australian Curriculum Assessment and Reporting Authority. (2011). NAPLAN achievement in reading, persuasive writing, language conventions and numeracy: National report for 2011. Sydney, Australia: ACARA.

Beresford, Q., \& Gray, J. (2006). Models of policy development in Aboriginal education: Issues and discourse. Australian Journal of Education, 50(3), 265-280.

Bourke, C. J., Rigby, K., \& Burden, J. (2000). Better practice in school attendance. Improving the school attendance of indigenous students. Canberra, Australia: Commonwealth of Australia.

Collins, B., \& Lea, T. (1999). Learning lessons: An independent review of indigenous education in the Northern Territory. Darwin, Australia: Northern Territory Department of Education.

Comaskey, E., Savage, R., \& Abrami, P. C. (2009). A randomized efficacy study of web-based synthetic and analytic programmes among disadvantaged urban kindergarten children. Journal of Research in Reading, 32(1), 92-108.

Hargreaves, A. (1998). The emotional practice of teaching. Teaching and Teacher Education, 14(8), $835-854$.

Hargreaves, A. (2001). Emotional geographies of teaching. Teachers College Record, 103(6), 1056-1080.

Harper, H., Helmer, J., Lea, T., Chalkiti, K., Emmett, S., \& Wolgemuth, J. R. (2012). ABRACADABRA for magic under which conditions? Case studies of a web-based literacy intervention in the Northern Territory. Australian Journal of Language and Literacy, 35(1), 33-50.

Harris, J. (2007). Linguistic responses to contact: Pidgins and creoles. In G. Leitner \& I. G. Malcolm (Eds.), The habitat of Australia's Aboriginal languages: Past, present, and future (pp. 131-151). Berlin, Germany: Mouton de Gruyter.

Hipps, G., Abrami, P. C., \& Savage, R. (2005). ABRACADARA: The research, design and development of web-based early literacy software. In S. Pierre (Ed.), Développement, intégration et évaluation des technologies de formation et d'apprentissage (DIVA). Innovations et tendances en technologies de formation et d'apprentissage (pp. 89-112). Montreal, Canada: Presses Internationales Polytechnique.

Holodynski, M. (2009). Milestones and mechanisms of emotional development. In B. Rötger-Rössler \& H. J. Markowitsch (Eds.), Emotion as bio-cultural processes (pp. 139-163). New York, NY: Springer.

Hughes, H., \& Hughes, M. (2010). Indigenous education 2010. St Leonards, Australia: Centre for Independent Studies.

Kelchtermans, G. (2005). Teachers' emotions in educational reforms: Self-understanding, vulnerable commitment and micropolitical literacy. Teaching and Teacher Education, 21, 995-1006. 
Ladwig, J. G., \& Sarra, C. (2009). Structural review of the Northern Territory Department of Education and Training: Delivering the goods. Darwin, Australia: Northern Territory Department of Education and Training.

Lasky, S. (2005). A sociocultural approach to understanding teacher identity, agency and professional vulnerability in a context of secondary school reform. Teaching and Teacher Education, 21(8), 899-916.

Lea, T., Thompson, H., McRae-Williams, E., \& Wegner, A. (2011). Policy fuzz and fuzzy logic: Researching contemporary indigenous education and parent-school engagement in north Australia. Journal of Education Policy, 26(3), 321-339.

Little, J. W. (1996). The emotional contours and career trajectories of (disappointed) reform enthusiasts. Cambridge Journal of Education, 26(3), 345-359.

Luke, A., Green, J., \& Kelly, G. J. (2010). Introduction: What counts as evidence and equity? Review of Research in Education, 34, 7-16.

National Institute of Child Health and Human Development. (2000). Report of the National Reading Panel. Teaching children to read: An evidence-based assessment of the scientific research literature on reading and its implications for reading instruction, reports of the subgroups (NIH Publication No. 00-4754). Washington, DC: US Government Printing Office.

Nias, J. (1993). Changing times, changing identities: Grieving for a lost self. In R. G. Burgess (Ed.), Educational research and evaluation: For policy and practice (pp. 139-156). London, England: Farmer Press.

Nias, J. (1996). Thinking about feeling: The emotions in teaching. Cambridge Journal of Education, 26(3), 293-306.

O'Connor, K. E. (2008). "You choose to care": Teachers, emotions and professional identity. Teaching and Teacher Education, 24, 117-126.

Pearson, N. (2009). Radical hope: Education and equality in Australia. Quarterly Essay, 35, 1-105.

Pearson, N. (2010). Some magic bullets for education. The Australian. Retrieved March 27 from 2010 http://www.theaustralian.com.au/news/opinion/some-magic-bullets-for-education/story-e6frg6zo-12 25846160455.

Ramsey, G., Cummins, G., Hansen, T., \& Wauchope, L. (2009). New ownership, new responsibilities. Review of education in the Groote Eylandt and Bickerton Island region. APPENDIX 6 Programs and approaches to Indigenous Education. Alyangula, Australia: Anindilyakwa Land Council.

Roth, W.-M. (2007). Emotion at work: A contribution to third-generation cultural-historical activity theory. Mind, Culture, and Activity, 14(1-2), 40-63.

Sharplin, E. (2002). Rural retreat or outback hell: Expectations of rural and remote teaching. Issues in Educational Research, 12(1), 49-63.

Smagorinsky, P., \& Daigle, E. A. (2012). The role of affect in students' writing for school. In E. L. Grigorenko, E. Mambrino, \& D. D. Preiss (Eds.), Writing: A mosaic of new perspectives (pp. 293-307). New York, NY: Psychology Press.

Sutton, R. E., \& Wheatley, K. F. (2003). Teachers' emotions and teaching: A review of the literature and directions for future research. Educational Psychology Review, 15(4), 327-358.

Taylor, A., \& Dunn, B. (2010). Conceptualising and measuring the mobility of indigenous students in the Northern Territory. Australian Journal of Indigenous Education, 39, 88-97.

Vygotsky, L. (1986). Thought and language. Cambridge, MA: MIT Press.

Warren Little, J., \& Bartlett, L. (2010). The teacher workforce and problems of educational equity. Review of Research in Education, 34, 285-328.

Wertsch, J. V. (1998). Mind as action. New York: Oxford University Press.

Wolgemuth, J. R., Helmer, J., Harper, H., Chalkiti, K., Lea, T., Kirby, A., et al. (2011). ABRACADABRA (ABRA) Early Childhood Literacy Project, Annual Report No. 3: A Multi-site Randomised Controlled Trial and Case Study of the ABRA Literacy Software in Northern Territory Schools. Darwin, Australia: Menzies School of Health Research.

Yarrow, A., Ballantyne, R., Hansford, B., Herschell, P., \& Millwater, J. (1999). Teaching in rural and remote schools: A literature review. Teaching and Teacher Education, 15(1), 1-13.

Zembylas, M. (2002). Constructing genealogies of teachers' emotions in science teaching. Journal of Research in Science Teaching, 39(1), 79-103. 


\section{Author Biography}

Helen Harper is interested in pedagogies of language and literacy, and the question of how 'good teaching' is learned and sustained in different cultural settings. Helen has worked on a number of research projects relating to literacy interventions in the Northern Territory and this has led to her interest in exploring the discourses of success and failure in Aboriginal Education. Helen is currently a researcher at the Centre for Child Development and Education within the Menzies School of Health Research in Darwin. 